\title{
Simulation of 2D Saint-Venant equations in open channel by using MATLAB
}

\author{
Kamboh S. A \\ Department of Mathematics \& Statistics \\ Faculty of Science, QUEST \\ 67450 Nawabshah, Pakistan \\ e-mail: shakeel.maths@yahoo.com
}

\author{
Izzatul N. S, Labadin J. \\ Department of Computational Science \& Mathematics \\ Faculty of Computer Science \& \\ Information Technology, UNIMAS \\ e-mail: sinabila@fit.unimas.my \\ e-mail: ljane@fit.unimas.my
}

\author{
Monday O. Eze \\ Department of Computer Science/Maths/Informatics \\ Federal University Ndufu-Alike, \\ Ikwo (FUNAI), Ebonyi State, Nigeria \\ e-mail: eze_monday@yahoo.com
}

\begin{abstract}
D surface flow models are useful to understand and predict the flow through breach, over a dyke or over the floodplains. This paper is aimed at the surface flows to study the behavior of flood waves. The open channel water flow in drains and rivers is considered in view of the fact that such flows are the source of flash flood. In order to predict and simulate the flood behavior, a mathematical model with the initial and boundary conditions is established using 2D Saint-Venant partial differential equations. Next, the corresponding model is discretized by using the explicit finite difference method and implemented on MATLAB. For the testing and implementation purpose a simple rectangular flow channel is considered. The output parameters like height or depth of water $z(\mathrm{~m})$, the fluid velocity $\boldsymbol{u}$ $(\mathrm{m} / \mathrm{s})$ and the volumetric flow rate $Q\left(\mathrm{~m}^{3} / \mathrm{sec}\right)$ are simulated numerically and visualized for the different time steps. The initial simulation results are useful to understand and predict the flood behavior at different locations of flow channel at specific time steps and can be helpful in early flood warning systems. It is also suggested that the coupling of the subsurface flow with the surface flow may provide even better approximations for the flood circulation.
\end{abstract}

Keywords: Surface flow; open channel; Saint-Venant equations; shallow water equations; finite difference method, numerical simulation, MATLAB programming.

\section{Introduction}

Flood is the most frequently occurring natural disaster that not only affects the large population and the agricultural lands but also results in the loss of human life and damage of infrastructure [1]. Increased runoff rates due to urbanization, prolonged rainfall and inadequate river capacity are some of the major causes of the flood occurrences. It is very important to understand the behavior of water flow in the flow channels for early flood disaster management and also for saving human life. In early days, the methods used to predict the daily flows were limited to forecast only at the cross sections of flow channels and some times appeared to be unsuitable [2]. The mathematical models are quite useful to govern the fluid flow of different phenomenon including the surface flow, subsurface flow and coupled flows. In this regards, various studies have been done for the modeling of flood events at floodplains. For the one dimensional applications the flood wave propagation dynamic equations were proposed by [3] and are commonly known as SaintVenant (SV) equations. These equations are widely used to predict the surface flow parameters such as velocity, depth or height and the flow rate. For the two dimensional surface flow the SV equations are derived from the Navier-Stokes equations [4] and often referred to as Shallow Water (SW) equations. The derivation of SW equations and some of its variants can be found in [5]. Due to the non-linear nature of SV equations, the analytical solution is quite difficult. Therefore, the different numerical techniques have been proposed to obtain the surface flow simulations [6]. A numerical method based on the MacCormack finite difference scheme for simulating discontinuous two-dimensional overland shallow flow with spatially variable for micro topography was developed by [7]. The method is useful to simulate the rainfall-driven flash floods, flow in ephemeral stream channels, and tidal flat and wetland circulation. Another method based on an explicit finite difference scheme for micro topography was proposed by [8] which are useful for coupling overland surface flow and the infiltration processes during complex rainfall on natural slopes. [9] Presented explicit and implicit finite volume method schemes of the Roe type to model extreme unsteady, rapidly varied, open channel surface flow described by the SV equations. The numerical solution schemes devised by [9] are useful to simulate the transient flow, when discontinuities such as hydraulic jumps and bores exist. To analyze the depth of water surface in flood channel [10] proposed a numerical method to discretize the 1D SV equations. The 
results revealed that for the same value of roughness coefficient the smaller values of the bed slope of channel tend to high depth of water at specific time step. For simulating flood wave in the natural rivers [11] used SV equations and presented the numerical results of two different finite difference methods based on Preissmann and Lax diffusive schemes. They compared the hydrographs of both the methods with commercial simulation program HEC-RAS for the flow discharge and depth of water at $15 \mathrm{~km}$ upstream end and at the down stream end. It was concluded by [11] that the results obtained by Preissmann and Lax diffusive schemes are reasonably closed to each other but there was a poor agreement of these methods with the output results produced by HEC-RAS. One of the reasons of such disagreement in the results is the replacement of momentum equation by energy equation in the HEC-RAS model [12]. The four different methods based on either shallow water or kinematic wave equations to compare predictive abilities of flow model were presented by [13]. Their comparison shows that for the relatively simple configurations, kinematic wave equations solved with the finite volume method represent an interesting option but appears to be limited for case of discontinuous topography or strong spatial heterogeneities.

Recently, the topography, Geographic Information System (GIS), remote sensing and simulation system are widely used in the flood modeling. These models help to simulate runoff and stream flow in watershed with the application of GIS and remote sensing techniques to water resources managements [14]. One of the GIS based systems commonly used is the InfoWorks River Simulation (RS) [15] which is specifically used to identify the flood events and provides the clear pictures of floodplains. Various studies can be found in literature where such systems are effectively utilized as decision making tool in river basin planning. For instance, [16] demonstrated the post flood forensic analysis of Sungai Maong catchment at Kuching city of Sarawak, Malaysia using the Infoworks River Simulation (RS). The simulations obtained by RS were capable of providing a picture of the January 2000 flood event occurred in Kuching and also highlighted floodplains with pattern of floodwater spread. [16] Also employed RS to reconstruct the two extreme flood events of February 2003 and January 2004 floods at the flood-prone Sungai Sarawak Kanan and to obtain the flood hydrographs for the flooding of Bau town and surrounding areas. Although, the different systems are employed to flood flow modeling, they require long data sets and there modeling is complicated because of the approximate topography. Also, the governing equations in systems are predefined that limit the control of user on many hydrodynamic parameters. Therefore, this study aimed to model a simple finite difference model and write a user defined code in MATLAB that provides full control to the user on the hydrodynamic factors.

\section{Methodology}

The 2D Saint Venant equations are used to govern the surface flow. These equations are obtained from the continuity and momentum equations by depth averaging technique [18-19]. The basic assumptions used in the derivation of 2D SV equations are the hydrostatic pressure distribution and small channel slope. The governing equations for surface flow are obtained as follows:

$$
\begin{aligned}
& \frac{\partial z}{\partial t}+\frac{\partial(z u)}{\partial x}+\frac{\partial(z v)}{\partial y}=0, \\
& \frac{\partial(z u)}{\partial t}+\frac{\partial\left(z u^{2}+g z^{2} / 2\right)}{\partial x}+\frac{\partial(z u v)}{\partial y}=g z\left(S_{0 x}-S_{f x}\right), \\
& \frac{\partial(z u)}{\partial t}+\frac{\partial(z u v)}{\partial x}+\frac{\partial\left(z v^{2}+g z^{2} / 2\right)}{\partial y}=g z\left(S_{0 y}-S_{f y}\right) .
\end{aligned}
$$

Eq. (1) is the continuity equation and the Eqs. (2-3) are the momentum equations for $x$ momentum and $y$ momentum respectively; where $z(\mathrm{~m})$ is the water surface elevation (depth or height), $u(\mathrm{~m} / \mathrm{s})$ and $v(\mathrm{~m} / \mathrm{s})$ are the depth averaged velocity components in $x$ and $y$ directions respectively; $g\left(\mathrm{~m} / \mathrm{s}^{2}\right)$ acceleration of gravity, $S_{0 x}$ and $S_{f x}$ water surface gradient and friction resistance in $x$ direction, $S_{0 y}$ and $S_{f y}$ water surface gradient and friction resistance in $y$ direction and $t$ is the time step. Using the product rule of differentiation the Eqs. (1-3) can be further simplified as follows:

$$
\begin{aligned}
& \frac{\partial z}{\partial t}+u \frac{\partial z}{\partial x}+z \frac{\partial u}{\partial x}+v \frac{\partial(z)}{\partial y}+z \frac{\partial v}{\partial y}=0 \\
& z \frac{\partial u}{\partial t}+u \frac{\partial z}{\partial t}+u^{2} \frac{\partial z}{\partial x}+2 z u \frac{\partial u}{\partial x}+g u \frac{\partial u}{\partial x}+u v \frac{\partial z}{\partial y}+z v \frac{\partial u}{\partial y}+z u \frac{\partial v}{\partial y}=g z\left(S_{0 x}-S_{f x}\right), \\
& z \frac{\partial v}{\partial t}+v \frac{\partial z}{\partial t}+u v \frac{\partial z}{\partial x}+z v \frac{\partial u}{\partial x}+z u \frac{\partial v}{\partial x}+v^{2} \frac{\partial z}{\partial y}+2 z v \frac{\partial v}{\partial y}+g z \frac{\partial z}{\partial y}+=g z\left(S_{0 y}-S_{f y}\right) .
\end{aligned}
$$


In order to obtain the finite difference solution the Eqs. (4-6) are discretized using explicit finite schemes where the temporal and spatial derivatives are discretized by the following expressions;

$$
\frac{\partial u}{\partial t} \approx \frac{u_{i, j, k+1}-u_{i, j, k}}{\Delta t}, \frac{\partial u}{\partial x} \approx \frac{u_{i+1, j, k}-u_{i-1, j, k}}{2 \Delta x} \text { and } \frac{\partial u}{\partial y} \approx \frac{u_{i, j+1, k}-u_{i, j-1, k}}{2 \Delta y} \text {. }
$$

Thus the discretized set of equations takes the form as given in the following Eqs. (7-9);

$$
\begin{aligned}
& \frac{z_{i, j, k+1}-z_{i, j, k}}{\Delta t}+u_{i, j, k} \frac{z_{i+1, j, k}-z_{i-1, j, k}}{2 \Delta x}+z_{i, j, k} \frac{u_{i+1, j, k}-u_{i-1, j, k}}{2 \Delta x}+v_{i, j, k} \frac{z_{i, j+1, k}-z_{i, j-1, k}}{2 \Delta y}+z_{i, j, k} \frac{v_{i, j+1, k}-v_{i, j-1, k}}{2 \Delta y}=0, \\
& \left\{\begin{array}{l}
\frac{z_{i, j, k+1}-z_{i, j, k}}{\Delta t} u_{i, j, k}+z_{i, j, k} \frac{u_{i, j, k+1}-u_{i, j, k}}{\Delta t}+u_{i, j, k}^{2} \frac{z_{i+1, j, k}-z_{i-1, j, k}}{2 \Delta x}+2 z_{i, j, k} u_{i, j, k} \frac{u_{i+1, j, k}-u_{i-1, j, k}}{2 \Delta x}+g u_{i, j, k} \frac{u_{i+1, j, k}-u_{i-1, j, k}}{2 \Delta x}+u_{i, j, k} v_{i, j, k} \frac{z_{i, j+1, k}-z_{i, j-1, k}}{2 \Delta y}+z_{i, j, k} v_{i, j, k} \\
\times \frac{u_{i, j+1, k}-u_{i, j-1, k}}{2 \Delta y}+u_{i, j, k} z_{i, j, k} \frac{v_{i, j+1, k}-v_{i, j-1, k}}{2 \Delta y}=g z_{i, j, k}\left(S_{0 x}-S_{f x}\right)
\end{array}\right. \\
& \left\{\begin{array}{l}
\frac{z_{i, j, k+1}-z_{i, j, k}}{\Delta t} v_{i, j, k}+z_{i, j, k} \frac{v_{i, j, k+1}-v_{i, j, k}}{\Delta t}+u_{i, j, k} v_{i, j, k} \frac{z_{i+1, j, k}-z_{i-1, j, k}}{2 \Delta x}+z_{i, j, k} v_{i, j, k} \frac{u_{i+1, j, k}-u_{i-1, j, k}}{2 \Delta x}+u_{i, j, k} z_{i, j, k} \frac{v_{i+1, j, k}-v_{i-1, j, k}}{2 \Delta x}+v_{i, j, k}^{2} \frac{z_{i, j+1, k}-z_{i, j-1, k}}{2 \Delta y}+2 z_{i, j, k} v_{i, j, k} \\
\times \frac{v_{i, j+1, k}-v_{i, j-1, k}}{2 \Delta y}+g z_{i, j, k} \frac{z_{i, j+1, k}-z_{i, j-1, k}}{2 \Delta y}=g z_{i, j, k}\left(S_{0 y}-S_{f y}\right)
\end{array}\right\} .
\end{aligned}
$$

Eqs. (7-9) can be represented explicitly for $u_{i, j, k}, v_{i, j, k}$ and $z_{i, j, k}$ then can be solved iteratively. The finite difference approximations are performed on each grid point $(x, y, t)$. The fluid flow and water surface elevation is calculated for each time step and the distance along the flow channel. Since the free surface water flow in channels has many attractive applications including flood and subsurface flows. Therefore, for testing and implementation purpose a rectangular flow channel with free surface as shown in Figure 1 is considered. The finite difference discretization of the computational domain is also shown in Figure 2.

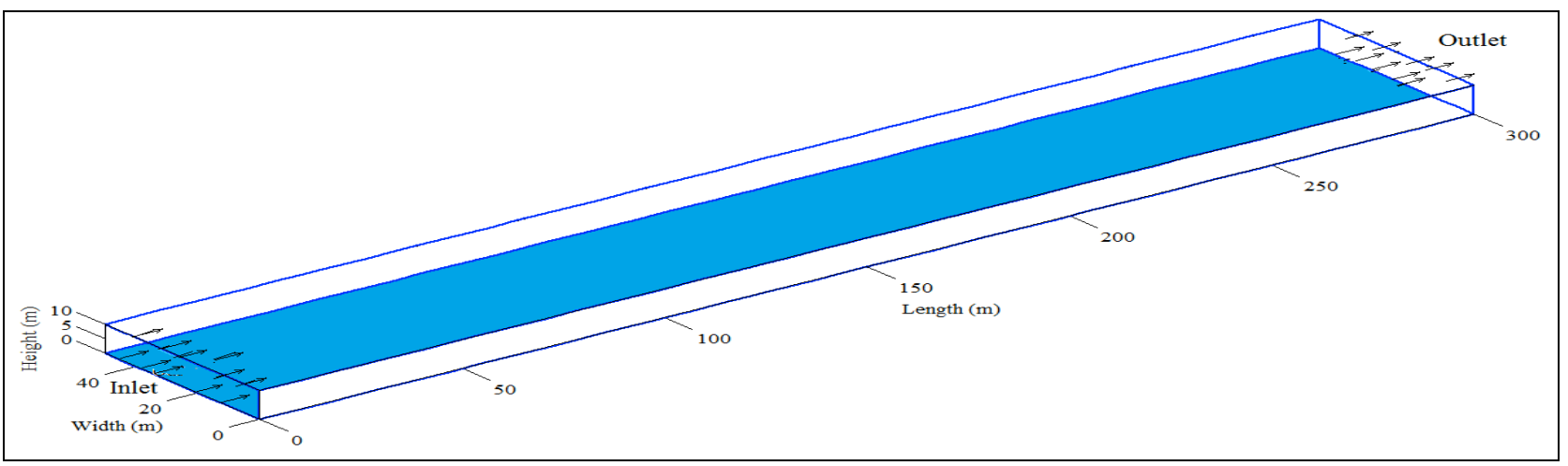

Figure 1. Schematic of an open channel with free surface

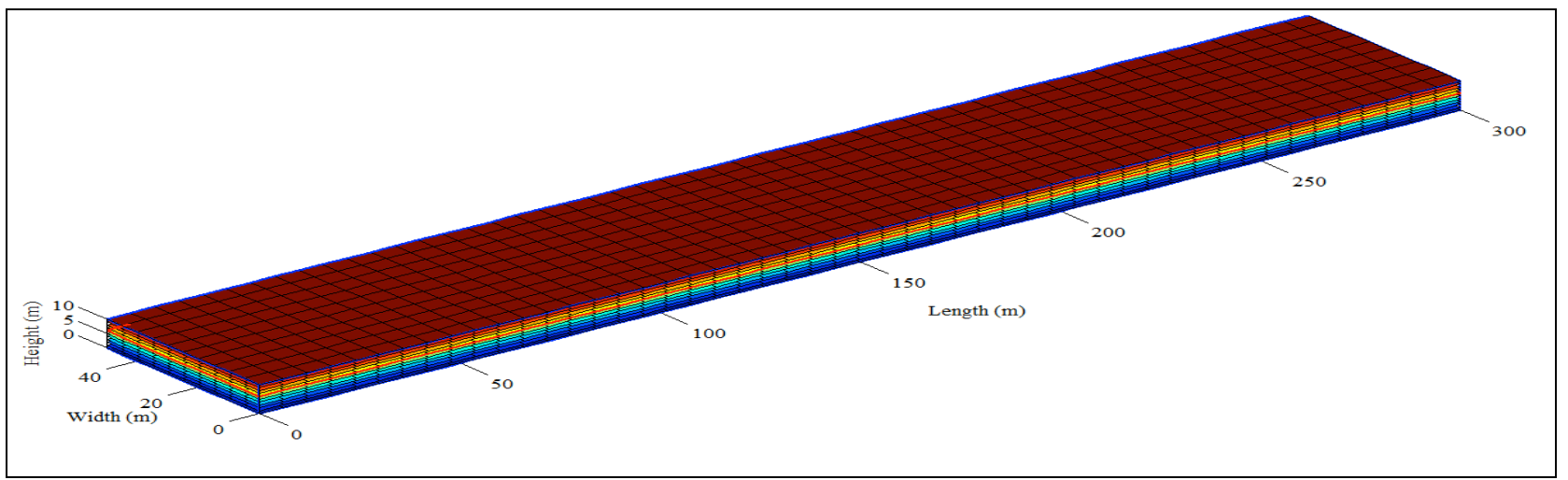

Figure 2. Finite difference discretization of open channel

In order to implement the numerical solution, a user defined code is written in MATLAB with the following data used in the model:

Flow channel dimensions; $\mathrm{L}=300(\mathrm{~m}), \mathrm{W}=50(\mathrm{~m}), \mathrm{H}=10(\mathrm{~m})$,

Initial conditions, $\mathrm{z} 0(\mathrm{x}, \mathrm{y})=0(\mathrm{~m}), \mathrm{u} 0=0, \mathrm{v} 0=0(\mathrm{~m} / \mathrm{s})$, 
$S_{0 x}=0, S_{f x}=0.1, S_{0 y}=0, S_{f y}=0.1$, generation of flood wave at inlet: $z=e^{\left.\left(-\left(a-a_{o}\right)^{2}+\left(b-b_{o}\right)^{2}\right) / k^{2}\right)}$, where $a$ and $b$ are the indices of each node along $x$ and $y$ axis respectively; $a_{o}$ and $b_{o}$ are the starting location of the flood column in $x$ and $y$ directions respectively, and $k$ is the initial height of the flood wave. For a hypothetical flood wave generated at inlet the test values are taken as $a_{o}=5, b_{o}=0$, and $k=10$.

\section{Simulation Results and Discussion}

The numerical solution for the output variables namely elevation of water $z(m)$, the velocity components $u(x, y)$ and $v(x, y)$ and the magnitude of velocity $\boldsymbol{u}(\mathrm{m} / \mathrm{s})$ are obtained for different time steps and then the simulation profiles are visualized for these variables. In addition, the volumetric flow rate $Q\left(\mathrm{~m}^{3} / \mathrm{s}\right)$ is also calculated from the results and visualized. Figure 3 exhibits the water elevation simulation profiles for different time steps. The profiles are useful to understand the variation in the depth or height of water surface at different regions of flow channels. Figure 3 shows the behavior of flood wave from inlet towards outlet. The local elevation of flood wave can be read at different time steps that gives the idea of the distribution of flood elevation near the inlet, inside flow channel and near the outlet. For example, it can bee seen from the color map that at the $N=100$ time steps the maximum water height above the surface (10 meters height) of flow channel reaches at 0.6 meters between $200(\mathrm{~m})$ and $270(\mathrm{~m})$ along the length of channel and between $10(\mathrm{~m})$ and $40(\mathrm{~m})$ along the width of flow channel. The local simulation profiles for the velocity component $u$ and $v$ are exhibited by Figure 4 and 5 respectively. The contribution of velocity components can easily be compared in the different regions of flow channel at different time steps. Similarly, the Figure 6 depicts the simulation profiles of the magnitude of velocity. The distribution of the water velocity at the different time steps is useful to predict the water movement. From the obtained simulation profiles for magnitude of velocity $\boldsymbol{u}$, one can estimate the time of arrival of flood wave from origin to any distance. As it can be noted that flood wave will cross the $150(\mathrm{~m})$ distance at $\mathrm{N}=50$ time steps. The volumetric flow rate $Q$ is also shown in Figure 7. The simulation profiles exhibit local flow rate of water at different time steps and useful to predict the discharge of water at any cross section of flow channel. It can be observed from the Figure 7 that the flow rate remains higher at the inlet and outlet, while it monotonically decrease from inlet to central regions of flow channel at different time steps. The results discussed in this study can help in the flood warning management systems if the original data is provided. This study was restricted to simple case of the flow channel where the effect of a single flood wave was analyzed numerically. But in practice, multiple flood waves may occur and many other unseen hydrodynamic parameters contribute to the surface flow propagation. Also, coupling of the subsurface flow with the surface flow may provide even better approximations for the flood circulation at different regions and specific time span [18-20].

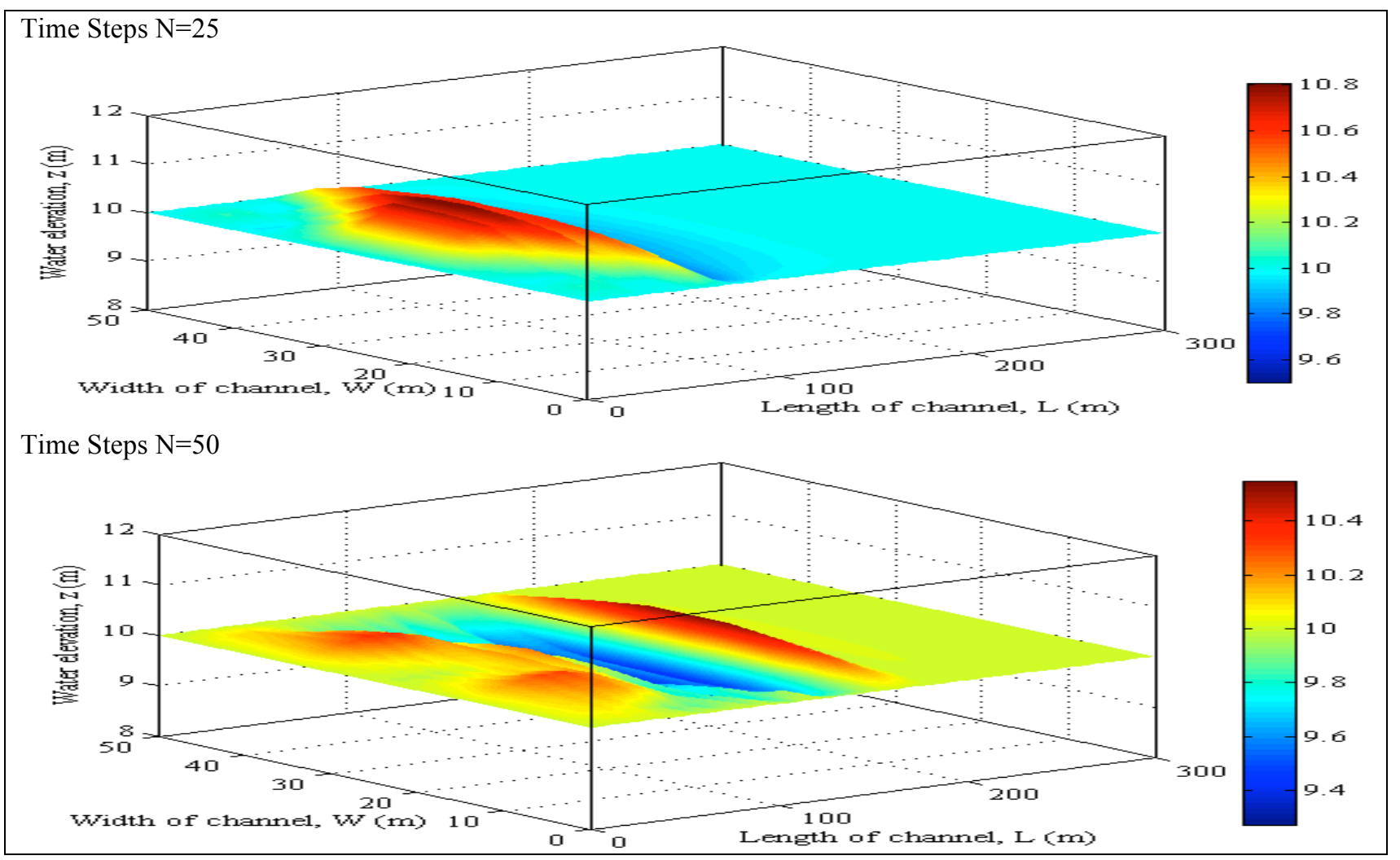




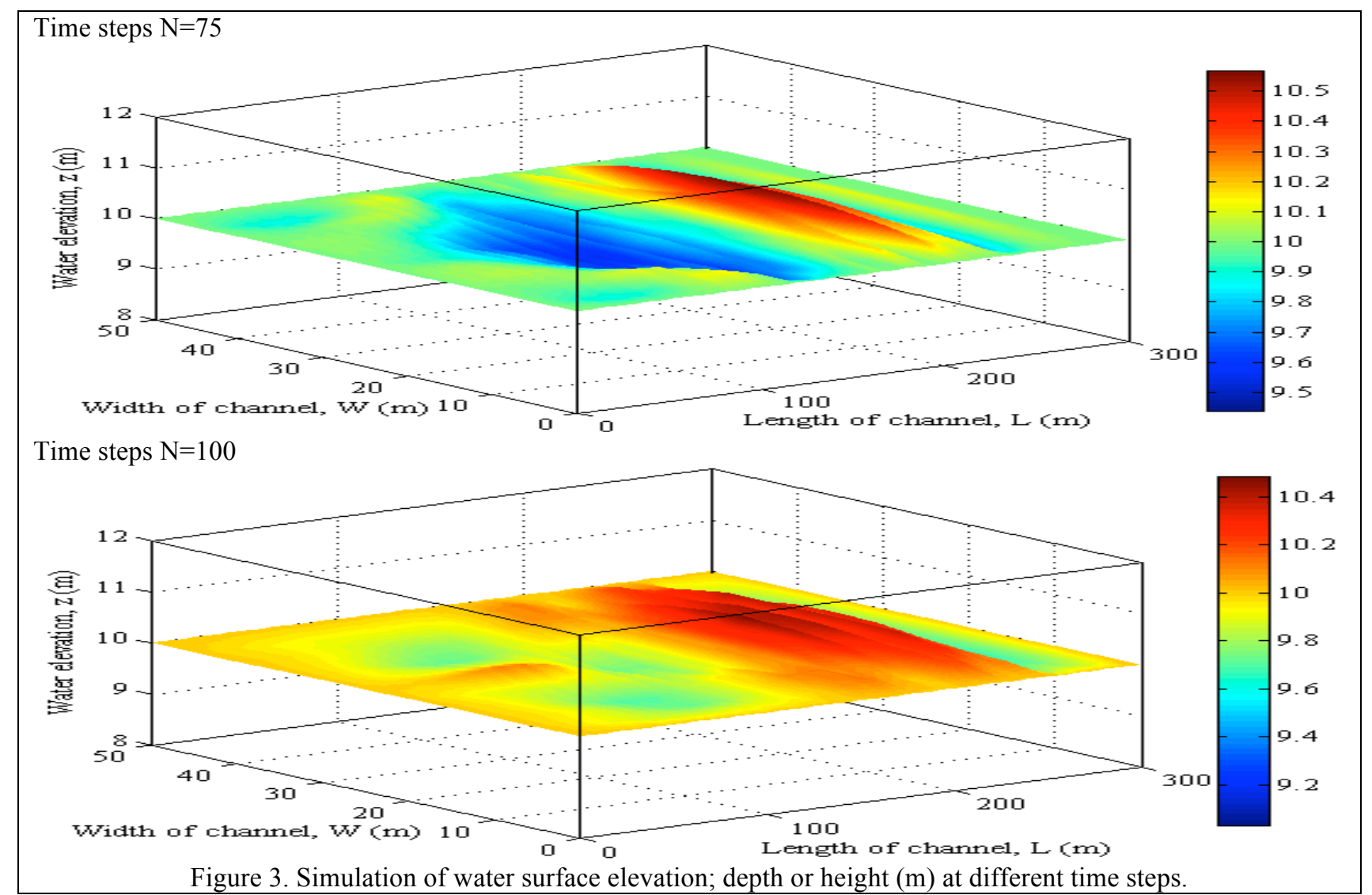

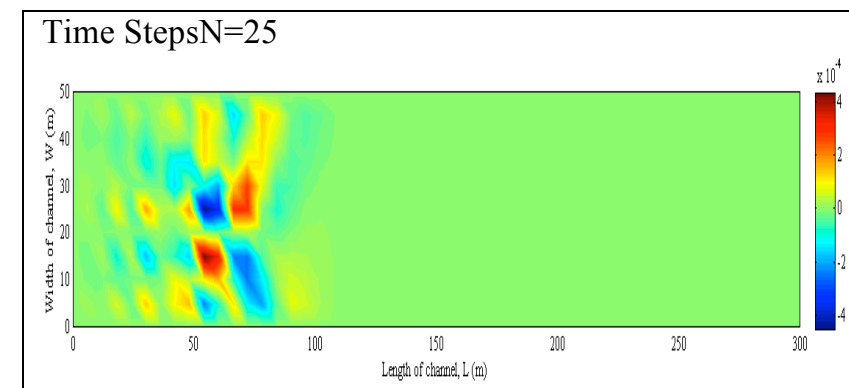

Time Steps N=50

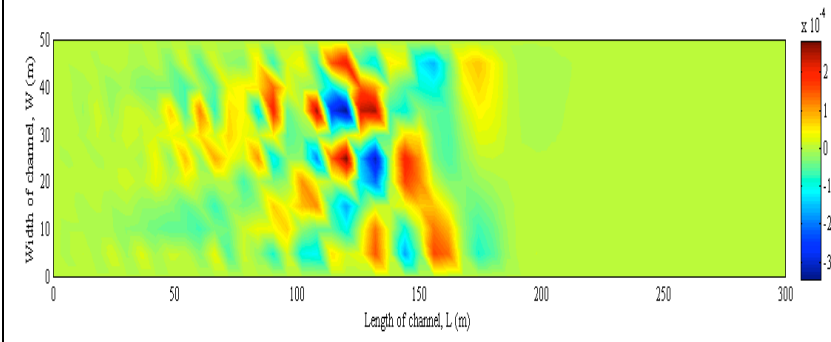

Time Steps N=75

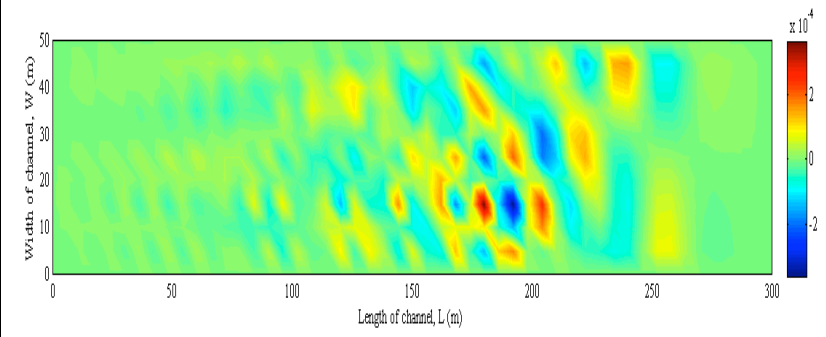

Time Steps $\mathrm{N}=100$
Time Steps $\mathrm{N}=25$

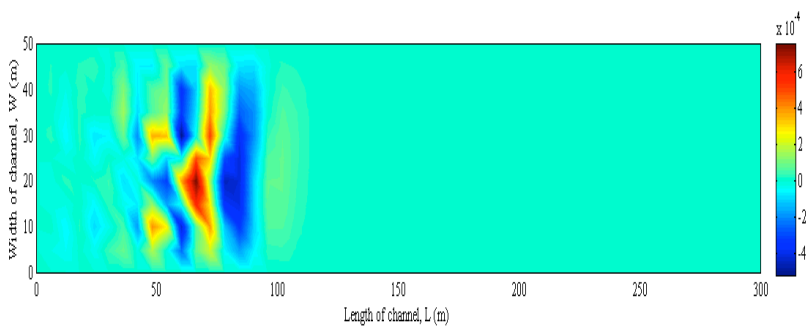

Time Steps $\mathrm{N}=50$

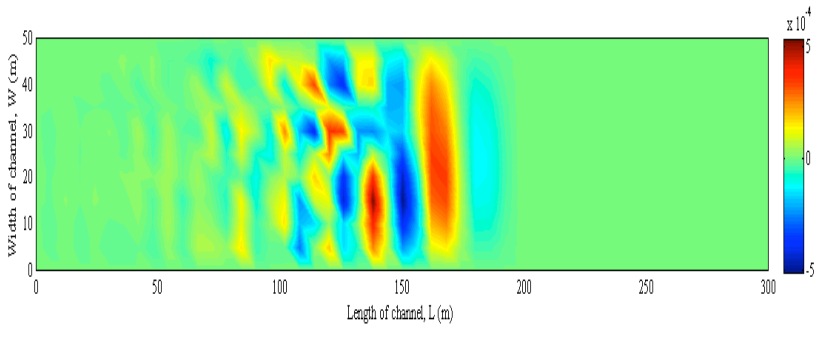

Time Steps N=75

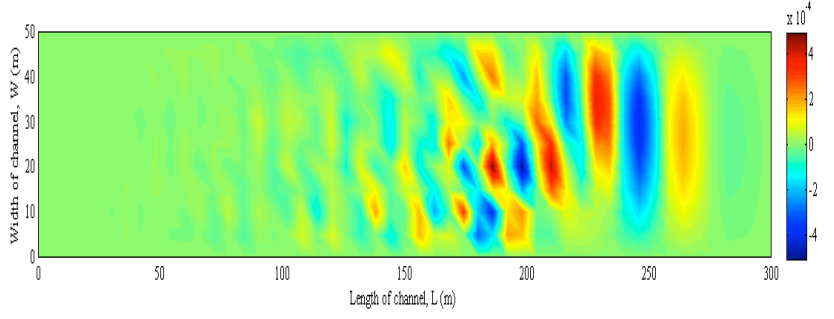

Time Steps N=100 


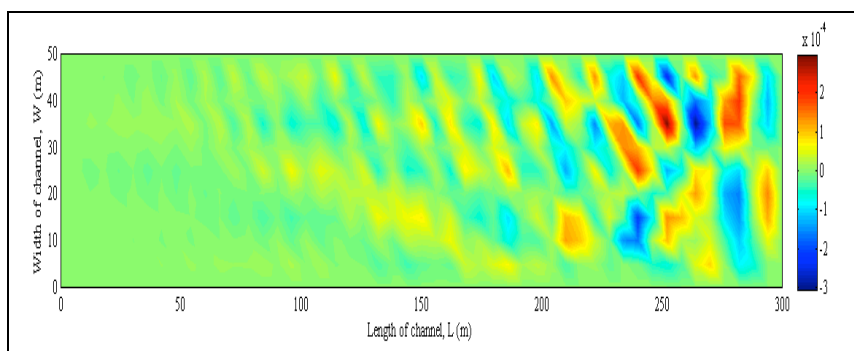

Figure 4. Simulation profiles of local velocity component $u(x, y)$ at different time steps.

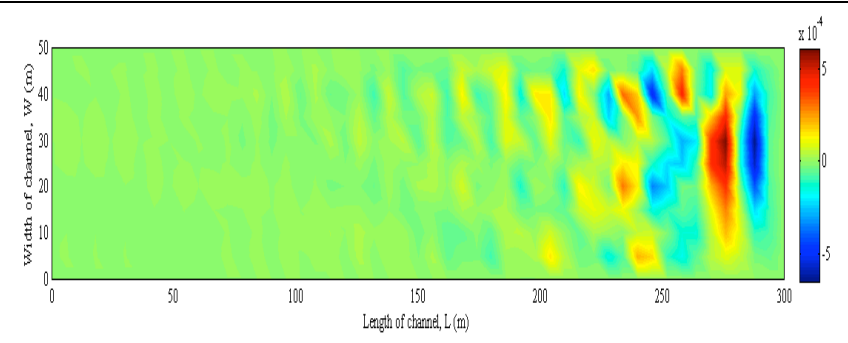

Figure 5. Simulation profiles of local velocity component $v(x, y)$ at different time steps.

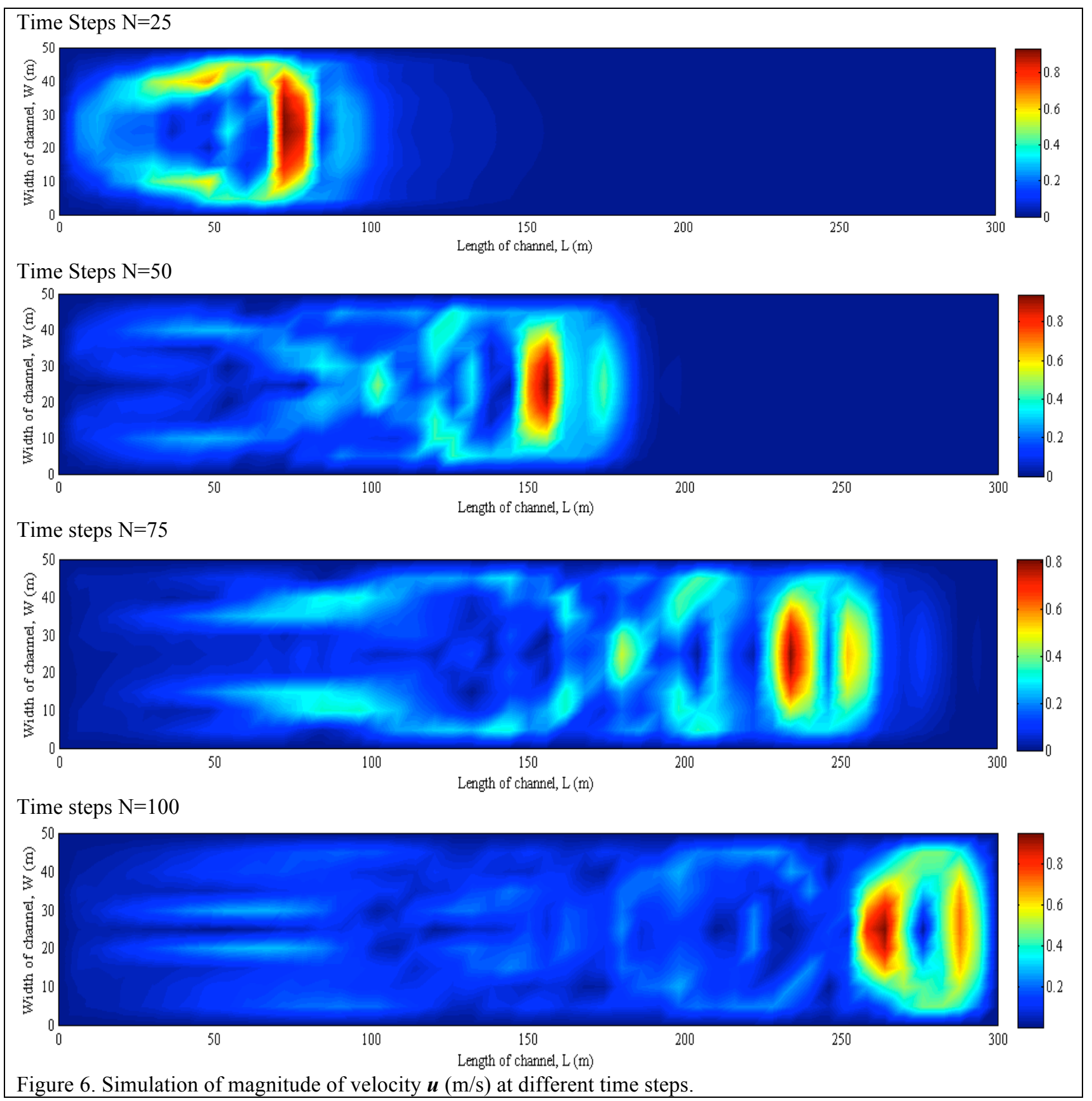




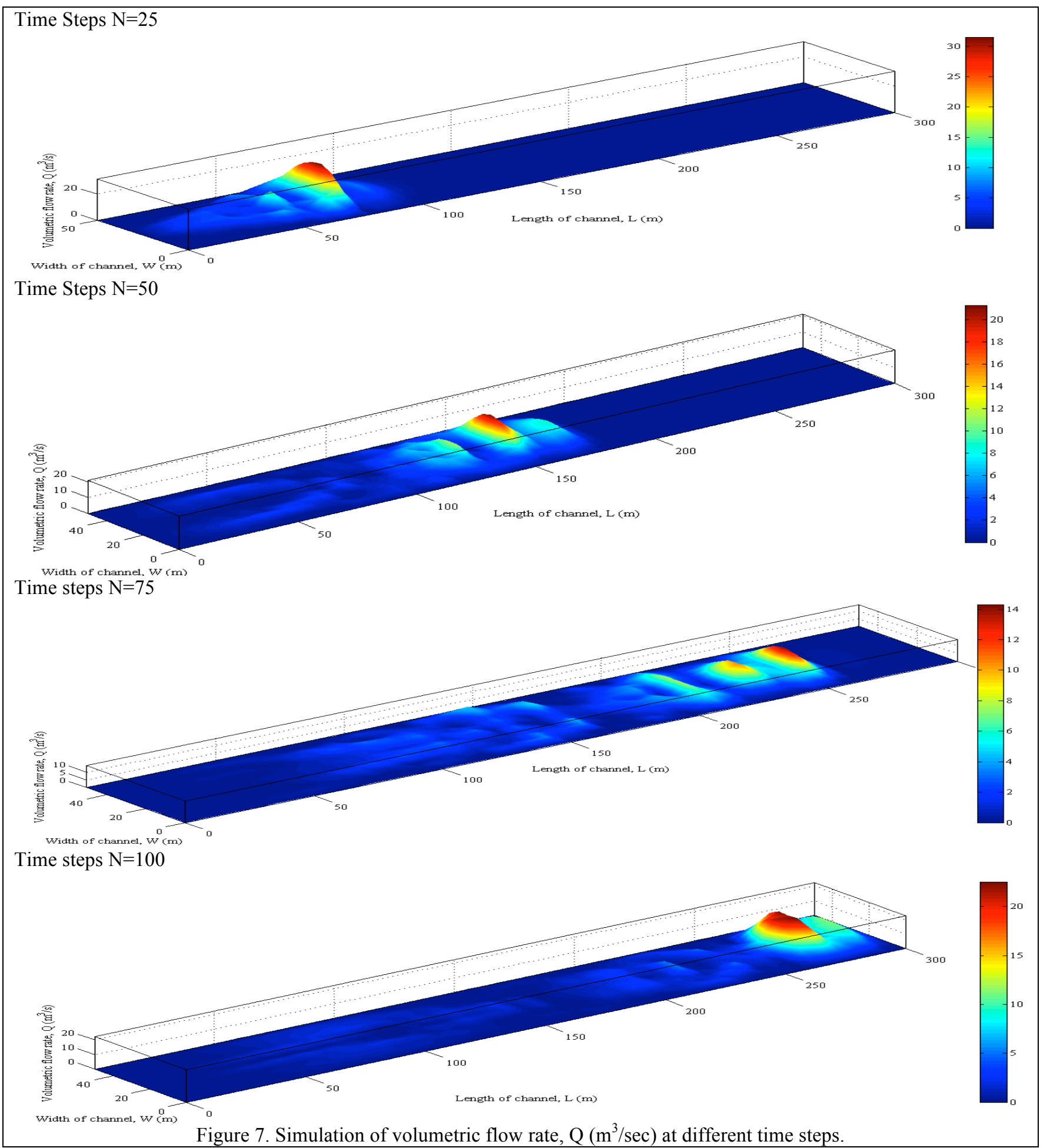

\section{Conclusion}

The two dimensional Saint-Venant shallow water equations are used to model and simulate the surface flow initiated by a flood wave in open channel. The equations are solved by a simple explicit finite difference method. A simple rectangular flow channel was considered with a hypothetical test flood wave at the inlet. The output variables of interest like depth of flow, velocity of water and the volumetric flow rate are simulated and visualized for the different time steps. Initial simulation results are realistic to understand the flood behavior at different space locations and time steps and can be helpful for the early flood disaster management. The future work will focus on the effects of multiple flood waves on the hydrodynamic parameters and the coupling of ground water and surface water flows in the open channels. 


\section{Acknowledgement}

This research is supported by Research Acculturation Grant Scheme (RAGS), Ministry of Higher Education (MOHE) which are managed by Research and Innovation Management Centre (RIMC), UNIMAS.

\section{References}

[1] P. Mujumdar, “Flood wave propagation," Resonance, vol. 6, pp. 66-73, 2001.

[2] I. Zheleznyak and L. Byshovets, "A mathematical model of flood waves moving along a cascade of reservoirs on a large river," Application of Mathematical Models in Hydrology and Water Resources Systems, 1975.

[3] B.D. Saint-Venant, "Theory of unsteady water flow, with application to river floods and to propagation of tides in river channels." French Academy of Science, 73, 148-154, 37-240,1871.

[4] C. Dawson and C. M. Mirabito, “The Shallow Water Equations”, 2008, Retrieved 10.02.2015.

[5] http://physics.nmt.edu/ raymond/classes/ph332/notes/shallowgov/ shallowgov.pdf

[6] C.B. Vreugdenhil, "Numerical Methods for Shallow-Water Flow", 1994, Kluwer Academic Publishers.

[7] F. R. Fiedler and J. A. Ramirez, "A numerical method for simulating discontinuous shallow flow over an infiltrating surface," International Journal for Numerical Methods in Fluids, vol. 32, pp. 219-239, 2000.

[8] M. Esteves, et al., "Overland flow and infiltration modelling for small plots during unsteady rain: numerical results versus observed values," Journal of hydrology, vol. 228, pp. 265-282, 2000.

[9] M. Szydłowski, "Implicit versus explicit finite volume schemes for extreme, free surface water flow modelling," Archives of Hydro-Engineering and Environmental Mechanics, vol. 51, pp. 287-303,2004.

[10] P. Chagas and R. Souza, "Solution of Saint Venant's equation to study flood in rivers, through numerical methods," Hydrology days, pp. 205-210, 2005.

[11] G. Akbari and B. Firoozi, "Implicit and explicit numerical solution of Saint-Venant equations for simulating flood wave in natural rivers", The 5th National Congress on Civil Engineering 2010, Mashad, Iran, 2010.

[12] HEC-RAS, User's Manual, Version 4.

[13] M. Rousseau et al.. "Overland Flow Modeling with the Shallow Water Eauations Using a Well-Balanced Numerical Scheme: Better Predictions or Just More Complexity,” Journal of Hydrologic Engineering, 04015012, 2015.

[14] N. Zheng, K. Takara, A. Y. Tachikaw and O. Kozan, "Analysis of Vulnerability to Flood Hazard Based on Land Use and Population Distribution in the Huaihe River Basin", China, Annuals of Disas. Prev. Res. Inst., Kyoto Univ., 51B, pp. 83-91, 2008.

[15] Wallingford Software, InfoWorks RS: “An Integrated Software Solution for Simulating Flows in Rivers in Channels and on Floodplains, ", Available from: http:/www.wallingfordsoftware.com/products/infoworks_rs/

[16] K. Jenny Kuihoon, et al., "Post-flood forensic analysis of Sungai Maong using InfoWorks TM River Simulation $(R S)$, , The Institution of Engineers, Malaysia, Vol. 68, No.4,41-46, 2007.

[17] Y. D. S. Mah, et al., "Use of infoworks river simulation (RS) in Sungai Sarawak Kanan modeling," The Institution of Engineers, Malaysia, Vol. 68, No. , 1-9, 2007.

[18] L. Zhu, et al., “Experimental Study and Numerical Modeling of Surface/Subsurface Flow at Field Scale,” Journal of Software, vol. 8, pp. 680-686, 2013.

[19] J. E. Liggett. "Water Flow and Solute Transnort Across the Surface-Subsurface Interface in Fully Integrated Hydrological Models," , PhD Thesis, . Flinders University, 2014.

[20] V. Casulli.. "A conservative semi-implicit method for coupled surface-subsurface flows in regional scale," International Journal for Numerical Methods in Fluids, 79, 199-214, 2015. 